\title{
ASPECTOS ESTRATÉGICOS E ECONÔMICOS DA POLIITICA DE BONIFICAÇÃO EM QUANTIDADE DE PRODUTO
}

\section{STRAIEGCANDECONOMCISSUES REGARDINGTOBONUS QUNIITYPOUCY}

\section{RESUMO}

Este trabalho objetiva identificar a percepção dos gestores de controladoria de indústrias sobre os aspectos estratégicos e econômicos da decisão de bonificação em quantidade de produto. A premissa é que os resultados econômicos gerados pela decisão de desconto no preço e de bonificação em quantidade de produto são iguais, considerando a mesma quantidade de produto entregue ao cliente. Com base no banco de dados da FIPECAFI- FEA-USP, analisaram-se 91 questionários encaminhados a controllers atuantes em diversos setores. Os resultados revelam: 1) um número muito significativo de empresas da amostra selecionada adota a bonificação em produtos; 2) a área comercial é a principal responsável por essa decisão; e 3) identificação da percepção dos controllers sobre aspectos decisórios de bonificação em quantidade de produtos.

\author{
Reinaldo Guerreiro \\ Professor do Departamento de Contabilidade e Atuária, Universidade de São Paulo - SP, Brasil \\ reiguerr@usp.br
}

\section{Maria Aparecida Gouvêa}

Professor do Departamento de Administração, Universidade de São Paulo - SP, Brasil

magouvea@usp.br

\section{Ariovaldo dos Santos \\ Professor do Departamento de Contabilidade e Atuária, Universidade de São Paulo - SP, Brasil \\ arisanto@usp.br}

Recebido em 11.04.2005. Aprovado em 30.06.2008.

Avaliado pelo sistema doubleblind review

Editor Científico: Francisco Aranha

\begin{abstract}
This article seeks to identify the perception of industrial controller managers have in regard to strategic and economic aspects of granting bonuses on higher product quantity purchases. The premise is that the economic results generated by the decision to grant a discount or a bonus for higher product quantities is much the same, taking into account the same amount of product delivered to the client. N inety-one surveys, from the FIPECAFI- FEA-USP database, answered by controllers working in a variety of sectors were analyzed. The results revealed the following: 1) a very significant number of companies from the selected sample adopt a product quantity bonus policy; 2) commercial departments are generally responsible for this decision; and 3) the perception of controllers in regard to decision-making aspects in regard to granting bonuses in relation to product amounts purchased.
\end{abstract}

PALAVRAS-CHAVE Bonificação em produto, desconto no preço, promoção de venda, rentabilidade de produto, política de preços. KEMORDS Bonus pack, price discount, sales promotion, product profitability, pricing policy. 


\section{INTRODUÇÃO}

A técnica de bonificação em quantidade de produtos é uma entre diversas formas de promoção de vendas, sendo muito comum em grandes empresas fornecedoras de produtos para 0 varejo, notadamente na indústria farmacêutica, havendo alguns trabal hos que abordam 0 assunto (REITER, 1994; FARHAMGMHER e BRITO, 1997; FRIEDMAN e LEWIS, 1999; JOHNSON e outros, 1999; KASS, 1994; KOPALLE e outros, 1999; ARCELUS e outros, 2001; GURNANI, 2001; MUNGER e GREWAL, 2001). U ma forma popular de promoção de vendas corresponde a ofertar aos compradores quantidades adicionais do produto sem aumento no preço estabelecido. Esse tipo de promoção de vendas é frequentemente denominado "bonificação em quantidade de produto". M uito embora a técnica de bonificação em quantidade de produtos tenha muita publicidade em revistas de negócios, essa técnica tem recebido pouca aten ção no ambiente acadêmico, existindo muitas questões sobre 0 assunto que merecem ser investigadas e discutidas.

O trabalho de Ong, Ho eTripp (1997, p. 102-112) aborda a questão da bonificação em quantidade de produto, investigando se essa técnica de promoção de vendas perde credibilidade quando o montante de quantidade bonificada aumenta muito em relação à quantidade-padrão de venda. A pesquisa desses autores identificou a percepção de consumidores finais, enfocando os pontos positivos e negativos dessa técnica de promoção de vendas. Uma conclusão importante do estudo é de que os consumidores pesquisados demonstram não dar muita credibilidade a esse tipo de promoção quando envolve agressiva oferta de quantidades extras.

Considerando um enfoque diferente, Smith e Sinhá (2000) investigaram o efeito da semântica e da estrutura de ofertas de bonificação em quantidade, tais como "desconto de 50\%", "compre duas, com $50 \%$ de desconto" e "compre uma, ganhe outra grátis". A pesquisa de Seibert (1997) demonstra que $75 \%$ dos consumidores respondentes acreditam que el es pagam direta ou indiretamente pelas quantidades grátis recebidas como bonificação. Esses resultados parecem indicar que desconto no preço é uma técnica de promoção de vendas mais efetiva que a bonificação em quantidade de produto.

Em estudo de custos comerciais, Schiff e outros (1991) observaram que os controllersnão incluem de forma adequada os elementos de custos comerciais no custo do produto. Essa observação está em linha com a conclusão do estudo de Foster e Grupta (1994) que mencionam que os custos comerciais têm recebido pouca atenção na literatura contábil.

Este estudo, inspirado no trabalho desenvolvido por Guerreiro e outros (2004), que aborda o tema da bonificação em produtos sob a óptica dos gestores comerciais, tem como objetivo identificar, por meio de pesquisa exploratória com um conjunto de empresas industriais selecionadas, a percepção dos controllers sobre os principais aspectos que direcionam e configuram a política de bonificação em quantidade de produto, bem como seus aspectos econômicos.

Como premissa, admite-se que os resultados econômicos das decisões de desconto no preço de venda e de bonificação em quantidades de produtos apresentam idêntico valor monetário quando se considera a mesma quantidade de produto entregue ao cliente. Nesse contexto, diversas questões se apresentam e direcionam as investigações deste trabal ho:

- Quais estratégias comerciais as empresas adotam? Empregam a política de bonificação em produtos juntamente com a política de desconto no preço ou somente uma dessas alternativas? Qual área da empresa decide sobre desconto no preço ou bonificação em quantidade?

- As empresas fornecem bonificação no mesmo produto vendido, ou a efetuam com outro produto? Qual a ordem de grandeza da quantidade de produtos entregue em bonificação?

- Quais os motivos que levam a empresa a utilizar a bonificação em quantidades em vez de desconto no preço? Quais objetivos a empresa busca atingir com a política de bonificação em produto e quais os principais pontos negativos de uma política de bonificação?

- Como a empresa calcula o custo de seus produtos? Como os controllers avaliam o custo para a empresa das unidades dadas em bonificação? Como o cliente avalia o benefício econômico das unidades recebidas em bonificação?

- Entre as empresas que adotam e não adotam bonificação em quantidade, há diferenças de opiniões sobre as seguintes variáveis de interesse da anál ise: (i) custo das unidades de produtos bonificadas; (ii) benefício econômico das unidades recebidas como bonificação; (iii) pontos negativos da utilização da política de bonificação em produtos; (iv) características de um produto para que este seja objeto de política de bonificação; e (v) cál culo dos custos dos produtos? Ou, em outras palavras, as opiniões das empresas sobre al guns aspectos da bonificação estão associadas ao fato de adotarem ou não bonificação em quantidade? 
Este artigo está estruturado em seis seções. Após esta introdução, são apresentados al guns conceitos teóricos que deram respaldo à realização da pesquisa deste trabalho. Assim, a segunda seção focaliza a análise da rentabilidade de produtos. A terceira seção, desdobrada em quatro subseções, detal ha aspectos econômicos da decisão de bonificação em quantidades. Na quarta seção, são feitas considerações sobre a coleta de dados, as variáveis do questionário e o teste qui-quadrado. A quinta seção exibe a análise dos resultados. Finalmente, a sexta seção apresenta as principais conclusões.

\section{ANÁLISE DA RENTABILIDADE DE PRODUTOS}

Diversos autores da área de contabilidade de custos e contabilidade gerencial, dentre os quais N oreen, Smith e Mackey (1995), demonstram que todo processo de análise e decisão envolvendo rentabilidade de produtos deve estar fundamentado em informações baseadas no método de custeio variável e utilização do conceito de margem de contribuição, ou margem de contribuição por fator limitativo na existência de fatores restritivos de produção.

Martins (2003) enfatiza que o método de custeio por absorção, através do rateio de custos fixos às unidades de produtos, distorce a rentabilidade dos produtos. Esse autor observa que a base conceitual da contabilidade de custos voltada para a tomada de decisões de rentabilidade é formada pelos conceitos de custeio variável, margem de contribuição de produtos, margem de contribuição de linhas e divisões e margem de contribuição por fator limitativo de produção. Horngren (1972) efetua sólida argumentação a favor da vantagem do custeio variável e do conceito de margem de contribuição em relação ao custeio por absorção.

Na obra de Goldratt (1992), é possível observar severa crítica ao método de custeio por absorção e custeio por atividades, bem como ao conceito de custo total do produto. A crítica se fundamenta na distorção do custo e da rentabilidade do produto provocada pela alocação dos custos fixos. 0 ideal izador da teoria das restrições enfatiza o gerenciamento de restrições e a aplicação do conceito de throughput, que, na verdade, corresponde ao conceito de margem de contribuição do produto.

Guerreiro e Angelo (1999) apresentam um modelo para a decisão de preços e análise de rentabilidade, processo operacional izado com base nos conceitos de custeio variável e margem de contribuição. A partir da aplicação dos conceitos de custeio variável e de margem de contri- buição, é possível estabelecer a equação de lucro válida para qualquer empresa de negócios:

$q v \cdot p v u-q v \cdot c v u-c f t=r e$

onde:

qv = quantidade produzida/vendida

pvu $=$ preço de venda unitário do produto

$\mathrm{cvu}=$ custo variável unitário do produto

$\mathrm{cft}=$ custo fixo total

re $=$ resultado da empresa

A equação (1) de lucro materializa a lógica do modelo de decisão de rentabilidade, cujo objetivo pode ser expresso da seguinte forma: a otimização do lucro global da empresa efetua-se por meio da otimização da margem de contribuição total dos produtos e do estabelecimento da estrutura ótima de custos fixos da empresa. Assim, toda decisão sobre produto, que não tenha influência na estrutura de custo fixo da empresa, deve ser orientada pela regra de otimização da margem de contribuição total dos produtos.

Um aspecto importante que pode ser deduzido dessas reflexões é que o custo que pode ser diretamente alocado ao produto é formado somente pelos custos variáveis. 0 custo fixo da empresa é sempre um custo periódico global e associado à estrutura da empresa. Dessa forma, ele não se relaciona diretamente com as unidades de produtos (nem vendidas nem bonificadas). As decisões de bonificação em quantidades envolvem entrega de unidades físicas dos produtos sem ônus para os clientes e, de acordo com a abordagem do método de custeio variável, o custo do produto bonificado é sempre o custo variável.

\section{ASPECTOS ECONÔMICOS DA DECISÃO DE BONIFICAÇÃOO EM QUANTIDADES}

Com base nas considerações sobre análise de rentabilidade de produtos efetuadas na seção anterior, são efetuadas a seguir reflexões sobre o significado econômico da decisão de bonificação em quantidade de produtos.

\section{Comparando o percentual de desconto no preço com o percentual de bonificação em quantidades}

Em princípio, pode parecer que o resultado da decisão de bonificação em produtos é mais vantajoso do que o resultado do desconto no preço de venda, uma vez que 
o custo do produto bonificado é somente o custo variável. No entanto, conforme se demonstra a seguir, os resultados da bonificação em produtos e do desconto no preço de venda são exatamente iguais, considerando-se determinadas condições. A comparação entre o resultado econômico das decisões de desconto no preço e o de bonificação em quantidade de produto deve ser orientada pela seguinte premissa básica: assumir na decisão do desconto e na decisão de bonificação a mesma quantidade entregue ao cliente.

Como previamente mencionado, para que os resultados gerados pel as decisões possam ser comparados, deve existir equivalência econômica entre o percentual de desconto no preço e o percentual de bonificação em quantidade de produto. As formas usuais de bonificação em quantidade de produto são expressas em quantidades físicas, quando, por exemplo, a empresa vende 100 unidades de produtos e entrega 140, ou, ainda, na forma relativa, quando a empresa entrega certo percentual a mais de quantidade em relação à efetivamente vendida, como, por exemplo, $40 \%$ a mais de unidades.

Para o cál culo correto do percentual de bonificação que tenha o mesmo sentido econômico do desconto no preço, é preciso efetuar a rel ação entre as quantidades bonificadas e o total das quantidades recebidas pelo cliente. No caso em que o cliente paga 100 e leva mais 40 unidades adicionais bonificadas, 0 cál culo do percentual equivalente ao desconto no preço deve ser efetuado considerando-se a relação entre as 40 unidades bonificadas e o total de 140 unidades recebidas pelo cliente, ou seja, 28,57\%. A relação entre 40 unidades bonificadas e 100 unidades vendidas (40\%) não expressa corretamente essa equivalência.

\section{Resultado gerado pela decisão de bonificação}

Conforme mencionado anteriormente, o modelo de decisão que envolve a rentabilidade dos produtos tem como objetivo a otimização da margem de contribuição desses produtos. No caso da decisão de concessão da bonificação, o modelo é expresso na equação abaixo, obtida a partir da equação (1) apresentada na seção anterior.

$m c=(p v-c v) \cdot q v-(c v \cdot q b)$

onde:

$\mathrm{mc}=$ margem de contribuição

$\mathrm{pv}=$ preço de venda do produto

$\mathrm{CV}=$ custo variável do produto

$q v=$ quantidade efetivamente vendida

$\mathrm{qb}=$ quantidade bonificada
Observa-se que, com os dados do exemplo apresentado na seção anterior, a margem de contribuição total gerada pela decisão de conceder a bonificação de 40 unidades de produtos (adicionais às 100 unidades vendidas) é de $\$ 7.200$.

\section{Resultado gerado pela decisão de dar desconto no preço de venda}

A decisão de concessão de desconto no preço de venda também envolve a rentabilidade do produto e deve orientar-se pela lógica da otimização da margem de contribuição. 0 modelo de decisão de concessão de desconto no preço de venda é expresso na equação seguinte, obtida a partir da equação geral do lucro da empresa apresentada na seção anterior.

$m c=(p v-d e \cdot p v-c v) \cdot q v$

onde:

$\mathrm{mc}=$ margem de contribuição

$\mathrm{pv}=$ preço de venda do produto

de $=$ percentual de desconto expresso na forma centesimal

$\mathrm{cv}=$ custo variável do produto

qv = quantidade vendida

Substituindo as variáveis pelos mesmos valores da equação anterior (2), observa-se que os resultados das decisões de bonificação em quantidade de produto e de desconto no preço de venda são exatamente iguais. Isso ocorre porque a bonificação em quantidades equivale economicamente a um desconto de $28,57 \%$ sobre 0 preço de venda, conforme apresentado na primeira subseção desta seção.

\section{Determinação do custo da bonificação na existência de capacidade limitada de produção}

No caso em que a empresa se encontra com restrições que limitem seu volume de produção em relação à demanda do mercado, o sacrifício financeiro derivado de cada unidade de produto dada em bonificação corresponde ao próprio preço de venda e não mais ao custo variável, conforme se demonstra a seguir. Admitindo-se que a quantidade máxima que a empresa possa fabricar seja 140 unidades por período, que a demanda do mercado se situe em faixa superior a esse volume e que a política de bonificação em quantidades seja de $40 \%$, utilizando a equação (2), teríamos uma margem de contribuição de $\$ 7.200$.

Tendo em vista a capacidade limitada de produção, a empresa poderia vender as 140 unidades de produto sem 
necessidade da política de bonificação. Assim, ao adotarmos apenas o primeiro termo da equação (2), o seu resultado seria de $\$ 11.200$.

Deve-se observar que o valor da diferença entre as margens de contribuição é de $\$ 4.000$, ou seja, $\$ 11.200$ $\$ 7.200$, que, dividido pela quantidade de produto bonificada, corresponde ao preço de $\$ 100$. Dessa forma, quando a empresa está no limite de sua capacidade, o custo de uma unidade bonificada corresponde ao próprio preço de venda do produto e não ao seu custo variável. Em outras palavras, o custo das unidades dadas em bonificação neste caso é o custo de oportunidade das vendas perdidas, ou seja, $\$ 100$ por unidade.

\section{0 resultado das decisões de desconto no preço e de bonificação em quantidade para a empresa compradora}

Considerando-se os dados do exemplo anterior, o custo unitário efetivo para o cliente, na compra com bonificação em quantidades, corresponderia ao custo total pago dividido pelas unidades totais recebidas. 0 custo total corresponde ao total de quantidades compradas multiplicado pelo custo unitário negociado, ou seja, 100un.*\$100/ un. $=\$ 10.000$. 0 custo unitário efetivo corresponde a $\$ 10.000 / 140$ un. $=\$ 71,43 /$ un.

Tomando-se a compra com o desconto no preço, do valor total de $\$ 10.000$ seria deduzida a parcela de desconto equivalente a $28,57 \%$. Assim, o custo líquido seria de $\$ 10.000-\$ 2.857=\$ 7.143$, ou seja, um custo unitário efetivo de $\$ 71,43$, que corresponde a $\$ 7.143 / 100$ un.

\section{METODOLOGIA}

Como dissemos, o objeto desta pesquisa é a bonificação em quantidades de produtos na transação entre empresas fornecedoras e compradoras de bens. Tendo em vista a premissa de que o resultado econômico da decisão de desconto no preço de venda é exatamente igual ao resultado econômico da decisão de bonificação em quantidade de produto, quando se considera a mesma quantidade final de produto entregue ao cliente, procura-se, nesse momento, investigar diversos aspectos da política de bonificação em quantidade de produto com base na percepção dos controllers de empresas industriais.

Foram encaminhados questionários para 600 empresas pré-selecionadas, dos seguintes setores de atividade: (i) bebidas; (ii) alimentos; (iii) fumo ; (iv) higiene, limpeza e cosméticos; ( v) material de construção ; (vi) farmacêutico e (vii) plásticos e borracha. Utilizou-se o banco de dados da FIPECAFI (Fundação Instituto de Pesquisas Contábeis Atuariais e Financeiras), que é o mesmo utilizado para a elaboração da edição Melhorese Maiores, da Editora Abril.

Os resultados das 91 empresas que devolveram questionários corretamente respondidos são analisados em dois momentos distintos. Inicial mente, as variáveis são tratadas de forma isolada, procurando-se identificar suas características descritivas (enfoque univariado). Posteriormente, são analisados simultaneamente pares de variáveis, procurando-se identificar associações (enfoque bivariado). 0 Q uadro 1 sintetiza as questões, as alternativas eas escalas das variáveis utilizadas neste estudo.

Quadro 1 - Questões da pesquisa

QUESTÕES
Q.1 Estratégias comerciais de des-
contos adotadas
Q.2 Área decisora sobre a forma
de desconto
Q.3 Especificação da estratégia
de bonificação em quantidade de
produtos

Q.4 Volume físico de produto entregue a título de bonificação em percentual

\begin{tabular}{|c|}
\hline ALTERNATIVAS \\
\hline $\begin{array}{l}\text { Só desconto no valor do preço de venda; Só bonificação em } \\
\text { quantidades de produtos; Ambas; Nenhuma. }\end{array}$ \\
\hline Marketing; Finanças; Ambas as áreas; Outra. \\
\hline $\begin{array}{l}\text { Quantidades grátis do mesmo produto objeto da venda; } \\
\text { Quantidades grátis de produto diferente do produto vendido; } \\
\text { Ambas. }\end{array}$ \\
\hline $\begin{array}{l}\text { Faixas de percentual da quantidade de produto faturado: Até } \\
5 \% \text { da quantidade de produto faturado; Entre } 6 \% \text { e } 10 \% \text {; Entre } \\
11 \% \text { e } 20 \% \text {; Entre } 21 \% \text { e } 40 \% \text {; Acima de } 40 \% \text {. }\end{array}$ \\
\hline
\end{tabular}

VARIÁVEIS

ESCALAS

(continua)

\begin{tabular}{|l|l|}
\hline V2 & Nominal \\
\hline V3 & Nominal \\
\hline V4 & Nominal \\
\hline V5 & Ordinal \\
\hline
\end{tabular}


Q.5 Grau de concordância para cada objetivo pretendido com a política de bonificação em produtos

Q.6 Principal motivo para a empresa dar bonificação em unidades de produto

Q.7 Percepção do "custo" das unidades de produtos bonificadas para a empresa

Q.8 Percepção do "benefício econômico" das unidades recebidas em bonificação

Q.9 Grau de concordância para os pontos negativos da utilização da política de bonificação em produtos

Q.10 Grau de concordância para as características de um produto para que este seja objeto de política de bonificação

Q.11 Forma do cálculo dos custos dos produtos
V6 Aumento da participação de mercado; V7 Aumento no volume de vendas de um período específico; V8 Aumento do lucro do período específico; V9 Redução de custos; V10 Fidelização de clientes; V11 Fixação da marca; V12 Desova de estoque; V13 Venda rápida de produtos com prazo de validade vencendo; V14 Não prejudicar a imagem do produto vendido; V15 Agregar valor à venda e facilitar a negociação com 0 cliente.

Custo da bonificação é menor do que o custo do desconto; Cliente percebe a bonificação como mais vantajosa; Maior volume do produto no mercado.

Custo total de fabricação dos produtos (material direto, mãode-obra e gastos indiretos de fabricação); Custo total de fabricação mais despesas (administrativas, financeiras e de vendas); Somente o custo variável do produto (material direto e mão-de-obra direta); 0 preço de venda do produto.

Custo total de fabricação dos produtos recebidos; Custo total de fabricação mais despesas dos produtos recebidos; Somente 0 custo variável dos produtos recebidos; 0 preço de venda dos produtos recebidos.

V19 Não há nenhum ponto negativo relevante; V20 A imagem do produto fica prejudicada no mercado; V21 As quantidades de produtos bonificados "matam" vendas futuras.

V22 Ter consumo rápido; V23 Capacidade de produção acima da demanda de mercado; V24 Baixo custo unitário total de produção; V25 Baixo custo unitário variável de produção; V26 0 produto compete com muitos produtos concorrentes; V27 0 produto tem pequena margem de lucratividade; V2 8 Não existe fidelidade dos clientes ao produto.

V29 Pelo custo de fabricação do produto - custeio legal/ fiscal; V30 Pelo custo total, ou seja, além do custo de fabricação, são rateadas aos produtos as despesas administrativas, comerciais e financeiras; V31 Pelo custeio variável, ou seja, no custo do produto só entram os custos de matériasprimas e insumos variáveis; V32 Pelo custo de matéria-prima, mão-de-obra direta e insumos variáveis; V33 ABC - Activity Based Costing
Ordinal tipo escala Likert: 5 = concoda totalmente, 1 = discorda totalmente

V16

Nominal

V17 Nominal

V18 Nominal

V19 a V21

Ordinal tipo escala Likert: 5 = concorda totalmente, 1 = discorda totalmente.

Ordinal tipo escala Likert: 5 = concorda totalmente, 1 = discorda totalmente

\section{V29 a V33 Nominal}

A próxima seção apresenta os principais resultados no contexto univariado para todas as 11 questões. Posteriormente, apresentam-se os resultados no contexto bivariado para avaliar as associações entre variáveis, por meio do teste qui-quadrado. Essa técnica, cuja hipótese básica éa independência entre variáveis, foi utilizada para testar a associação entre pares de variáveis focalizadas neste trabalho. Esse teste é adequado para variáveis cuja escala é nominal ou ordinal.

Com nível de significância de 5\%, em geral, foi con- 
frontada a estatística qui-quadrado com o valor crítico extraído da tabel a qui-quadrado. 0 teste qui-quadrado de independência é válido somente se o tamanho da amostra for grande o suficiente para garantir a similaridade entre a distribuição teoricamente correta ea distribuição qui-quadrado amostral (AAKER, KUM AR eDAY, 1995, p. 480). É preciso também garantir que todos os valores esperados, sob a hipótese de independência, não sejam inferiores a cinco (BUSSAB e MORETTIN, 2002, p. 400).

A principal variável selecionada para o teste, materializada na questão 1 , corresponde à identificação das empresas que oferecem bonificação em quantidades de produtos. Criou-se a variável dicotômica com os níveis: adota a estratégia de bonificação (opções b e c) e não adota (a e d). Essa nova variável foi utilizada em todos os testes de independência e, em cada um, associada com outra variável pesquisada. As demais variáveis sel ecionadas foram extraídas das questões 7, 8, 9, 10 e 11.

Para se atender à condição de frequências esperadas maiores ou iguais a cinco, foi necessário agregar alguns níveis adjacentes da escala ordinal de concordância das variáveis 9 e 10. Os cinco níveis originais foram transformados em três: concorda (totalmente ou em parte), não concorda nem discorda e discorda (totalmente ou em parte).

As variáveis 7, 8 e 11, com escala nominal, foram transformadas em dicotômicas ou binárias, com dois tipos de classificação das empresas: 1 (um), quando a resposta converge com o referencial teórico; e 0 (zero), em caso contrário. Assim, essas questões receberam 1 (um) quando as respostas foram, respectivamente: somente o custo variável do produto (material direto e mão-de-obra direta) ou o preço de venda do produto, quando a empresa opera com capacidade limitada de produção; o preço de venda dos produtos recebidos; e pel o custo de fabricação do produto - custeio legal/fiscal.

\section{RESULTADOS OBTIDOS}

Conforme se disse anteriormente, realizaram-se dois tipos de análise: univariada e bivariada. Na primeira subseção, apresentam-se e discutem-se os resultados obtidos no primeiro tipo de análise. Em seguida, procede-se da mesma forma, explicitando os treze testes independentes e as suas hipóteses testadas.

\section{Análise Univariada}

Esta seção destaca as frequências das respostas para todas as 11 questões. Para tanto, anal isamos cada uma das respostas fornecidas pel os 91 controllers pesquisados. Ao final, sumarizamos os resultados em um quadro.

Estratégias comerciais

No que diz respeito às estratégias comerciais adotadas, das 91 empresas respondentes, um percentual muito significativo (50,5\%) adota tanto o desconto no preço como a bonificação em quantidade de produtos. Outros $35,2 \%$ adotam somente a estratégia de desconto no preço, sendo que $8,8 \%$ adotam somente a estratégia de bonificação em produtos e, apenas, 5,5\% das empresas responderam que não adotam nenhuma das duas estratégias.

\section{Departamento que toma a decisão}

Este quesito foi respondido por 54 empresas que praticam a política de bonificação em quantidade de produto. A área de marketing (que neste estudo abrange todas as áreas de função comercial da empresa) é a responsável pela decisão de desconto de quantidade versus desconto no preço na maioria das empresas (55,6\%); $33,3 \%$ das empresas responderam que a decisão é tomada conjuntamente pel as áreas de mark eting e finanças. Também pôde ser constatado que em 7,4\% das empresas pesquisadas a área de finanças é a única responsável pela tomada dessa decisão; em apenas duas empresas essa decisão é de outra área, no caso, da diretoria e da direção geral .

Implementação da estratégia da bonificação em produto $\mathrm{N}$ a maior parte das 54 empresas que adotam a bonificação em quantidade de produto ( 34 empresas ou $63 \%$ ), a estratégia de bonificação se materializa por meio da bonificação tanto de quantidade grátis do mesmo produto quanto de quantidade grátis de produto diferente daquele que foi vendido. Em outras 18 empresas (33,3\%) é empregada somente a bonificação em quantidade do próprio produto objeto da venda. A penas duas empresas responderam que utilizam a bonificação em quantidade com produto diferente daquele que é vendido.

\section{Percentual oferecido como bonificação em quantidade}

$\mathrm{N}$ a resposta desse quesito, foram consideradas as $52 \mathrm{em}$ presas que praticam a política de bonificação em quantidade do mesmo produto vendido. Para $82,7 \%$ dessas empresas, o percentual que expressa a relação entre as quantidades dadas em bonificação e as quantidades vendidas está na faixa de zero a $5 \%$. Em 17,3\% das empresas, 0 percentual de bonificação é maior que 0 citado anteriormente, caindo no intervalo de $6 \%$ a $10 \%$. Não houve resposta de empresas acima do limite superior deste último intervalo. 
Objetivos que a empresa espera atingir com a política de bonificação em produtos

$N$ a resposta desse quesito, foram consideradas as 52 empresas que praticam a política de bonificação em quantidade do mesmo produto vendido. Foram apresentados 11 objetivos para análise dos controllers, e observa-se que, aparentemente, não existe um objetivo único a ser destacado. A maior quantidade de respostas (39,6\%), pelo critério de avaliação "concorda totalmente", foi dada para o objetivo "agregar valor à venda e facilitar a negociação com o cliente". Considerando-se a soma dos dois critérios "concorda totalmente" e "concorda", nota-se que cinco são os principais objetivos: (a) agregar val or à venda e facilitar a negociação com o cliente (84,6\%) ; (b) fidelização de clientes $(82,7 \%)$; (c) aumento no volume de venda do período $(73,1 \%)$; (d) aumento da participação de mercado $(64,7 \%)$; (e) fixação da marca $(62,7 \%)$.

Os demais objetivos listados - aumento do lucro do período, redução de custos, desova de estoque (estoque excessivo), venda rápida de produtos com prazo de validade vencendo e não prejudicar a imagem do produto vendido - não são percebidos pel os controllers como importantes na definição da política de bonificação em produtos. Adicional mente, outros objetivos foram incluídos, dentre os quais se destacam: aumentar o estoque no cliente, efetivar a negociação e evitar atravessador.

Motivos para a empresa dar bonificação em quantidade em vez de desconto no preço

N essa questão, foram consideradas as respostas do conjunto de 52 empresas que praticam a bonificação em quantidade do mesmo produto vendido. Dentre os motivos listados para a empresa utilizar a política de bonificação em quantidade em vez da política de desconto no preço, o motivo "maior volume do produto é colocado no mercado do que com o desconto em preço, diminuindo a participação dos concorrentes" foi citado em $50 \%$ das respostas dadas. Em segundo lugar (26,9\%), ficou o motivo "o custo da bonificação para a empresa é menor do que o custo do desconto no preço". Apenas 13,5\% entendem que o cliente percebe a bonificação como mais vantajosa do que o desconto no preço. Deve-se observar que, para os controllers, o cliente não acredita que a bonificação de quantidade traga mais benefício que o desconto no preço, porém, para parte deles $(26,9 \%)$, essa política é interessante para a empresa, pois entendem que o custo da bonificação é menor que o custo do desconto. Devese ressaltar que, conforme demonstrado neste trabalho, o custo da bonificação em produtos é igual ao custo do desconto, considerando-se a premissa de que o cliente recebe o mesmo volume final de produto. Não sendo considerada essa premissa, as duas al ternativas comerciais tornam-se incomparáveis. Observa-se que 9,6\% dos 52 gestores declararam outros motivos para dar bonificação, tais como: desovar estoque; impedir que a concorrência saiba qual o verdadeiro preço que está sendo praticado para os diferentes clientes e atender à política comercial exigida pelo cliente.

Custo das unidades de produtos bonificadas

Boa parte dos controllers, $44 \%$ dos 91 respondentes (novamente a amostra toda), entende que o custo dos produtos bonificados é o custo total de fabricação (material direto, mão-de-obra e gastos indiretos de fabricação). Dentre os demais respondentes, $26,4 \%$ entendem que é o custo total de fabricação mais despesas (administrativas, financeiras e de vendas), e outros $20,9 \%$ acham que é o preço de venda. Apenas $6,6 \%$ dos gestores acham que é o custo variável e 2,1\% apresentaram outras respostas. Observouse também que 2,2\% dos gestores entendem o custo das unidades bonificadas de forma diferente das alternativas apresentadas, tratando-o como o custo total de fabricação mais o custo de entrega (logística).

\section{Como o cliente entende o benefício econômico das unidades recebidas como bonificação}

Dentre os 91 controllers respondentes, $80,2 \%$ acreditam que o cliente avalia o benefício econômico das unidades bonificadas como sendo o preço de venda dos produtos recebidos. Esse entendimento está em linha com os principais objetivos que se busca atingir com a política da bonificação em produtos eleitos pel os gestores respondentes: (a) agregar valor à venda e facilitar a negociação com 0 clientee (b) fidelização de clientes. Um percentual menor de gestores (11\%) acredita que o cliente aval ia o benefício econômico das unidades recebidas em bonificação como o custo total de fabricação dos produtos, 5,5\% como sendo somente o custo variável dos produtos e, ainda, 3,3\% como o custo total de fabricação mais despesas.

Pontos negativos da política de bonificação em produtos $\mathrm{N}$ ão existe um consenso entre os 91 controllers com relação aos pontos negativos da política de bonificação em produtos. De maneira geral, os respondentes estão divididos com relação à afirmação de que não há nenhum ponto negativo rel evante, uma vez que $39,6 \%$ concordam com a mesma e $42,8 \%$ discordam. Os respondentes estão igual mente divididos no que diz respeito à afirmativa de que o ponto negativo é que as quantidades de produtos bonificados matam vendas futuras, sendo que $36,2 \%$ 
concordam e 38,5\% discordam. Os controllers estão de acordo com a ideia de que a política de bonificação não prejudica a imagem do produto no mercado, uma vez que, questionados sobre a afirmativa de que o ponto negativo é que a imagem do produto fica prejudicada no mercado, $72,5 \%$ discordam e apenas $14,3 \%$ concordam. Alguns gestores apresentaram adicionalmente outros pontos negativos que não os mencionados no questionário, destacando-se, entre eles: 0 aumento da oferta de produtos no mercado, o aumento de impostos para a empresa, a não-transferência do benefício para o consumidor final e a maior probabilidade de o cliente praticar vendas informais.

Características do produto para que este seja objeto de política de bonificação

Considerando-se conjuntamente as respostas "concorda total mente" e "concorda", as características tidas como as mais importantes para que o produto seja objeto de política de bonificação foram: (i) quando o produto compete com muitos produtos concorrentes ( $71,4 \%)$; (ii) quando o produto tem consumo rápido ( $55 \%$ ); e (iii) quando a empresa tem capacidade de produção acima da demanda de mercado $(48,4 \%)$. As características consideradas como pouco rel evantes para que os produtos sejam objeto de política de bonificação foram: quando não existe fidelidade dos clientes ao produto, quando o produto tem baixo custo variável ou baixo custo total de produção, ou, ainda, quando o produto tem pequena margem de lucratividade.

\section{Como a empresa calcula os custos dos produtos}

Para essa questão foram admitidas respostas múltiplas, totalizando 113. Desse total, $44,2 \%$ assumem que a empresa calcula os custos dos produtos pelo custo de fabricação do produto (critério legal/fiscal). Isso está em linha com o que os gestores entendem ser o custo das unidades bonificadas para a empresa. Um número significativo de respostas (23\%) indica o custo total mais despesas, ou seja, além dos custos de fabricação, são rateadas aos produtos as despesas administrativas, comerciais e financeiras. Dentre os respondentes, $14,1 \%$ indicam a utilização do Activity Based Costing. Apenas 12,4\% referem-se ao cálculo do custo de matéria-prima, mão-de-obra direta e insumos variáveis, e 6,2\% ao cálculo do custo do produto pelo custeio variável puro (matérias-primas e insumos variáveis).

Final mente, o Quadro 2 sumariza e apresenta os principais resultados encontrados nesta etapa da pesquisa.

\section{Análise bivariada}

Foram realizados 13 testes de independência. As hipóteses testadas foram as seguintes:

Quadro 2 - Síntese dos resultados no contexto univariado

\section{QUESTÕES}

Q.1

Q.2

Q.3

Q.4

Q.5

Q.6

Q.7

Q.8

Q.9

Q.10

Q.11

\section{RESULTADOS}

50,5\%: política de desconto no preço e bonificação em quantidades, 59,3\% política de bonificação em quantidade de produtos, 40,7\% não adotam essa política, 35,2\% somente 0 desconto no preço de venda; 5,5\% nenhuma dessas políticas

55,6\%: a área comercial

63\%: através da entrega de quantidade grátis do mesmo produto objeto da venda ou de produto diferente

82,7\%: 0 volume de produto entregue a título de bonificação representa até $5 \%$ do faturado

as empresas buscam atingir vários objetivos com a política de bonificação em quantidades

maior quantidade de produto é colocada no mercado do que com o desconto em preço, diminuindo a participação dos concorrentes; 0 custo da bonificação para a empresa é menor do que o custo do desconto no preço

44\%: 0 custo das unidades bonificadas é o custo total de fabricação dos produtos

80,2\%: o cliente considera o benefício econômico das unidades bonificadas como sendo o preço de venda não existe consenso com relação aos pontos negativos da política de bonificação em quantidade de produtos as duas principais características: (1) o produto compete com muitos produtos concorrentes $(71,4 \%)$; $(2)$ ter consumo rápido (55\%)

$44,2 \%$ : pelo custo total de fabricação, de acordo com o critério legal; $23 \%$ pelo custo de produção mais despesas administrativas, comerciais e financeiras. 
$\mathrm{H}_{0,1}$ : a percepção correta do custo das unidades de produtos bonificadas independe da prática da estratégia de bonificação

$\mathrm{H}_{0,2}$ : a percepção correta do benefício econômico das unidades recebidas como bonificação independe da prática da estratégia de bonificação

$\mathrm{H}_{0,3}$ : a identificação de nenhum ponto negativo na utilização da política de bonificação em produtos independe da prática da estratégia de bonificação

$\mathrm{H}_{0,4}$ : a percepção de que a imagem do produto fica prejudicada com a política de bonificação independe da prática da estratégia de bonificação

$\mathrm{H}_{0,5}$ : a percepção de que as quantidades de produtos bonificados "matam" vendas futuras com a política de bonificação independe da prática da estratégia de bonificação

$\mathrm{H}_{0,6}$ : a percepção de que o produto precisa ter consumo rápido para ser objeto de política de bonificação independe da prática da estratégia de bonificação

$\mathrm{H}_{0,7}$ : a percepção de que o produto precisa ter capacidade de produção acima da demanda de mercado para ser objeto de política de bonificação independe da prática da estratégia de bonificação

$\mathrm{H}_{0,8}$ : a percepção de que o produto precisa ter baixo custo unitário total de produção para ser objeto de política de bonificação indepen de da prática da estratégia de bonificação

$\mathrm{H}_{0,9}$ : a percepção de que o produto precisa ter baixo custo unitário variável de produção para ser objeto de política de bonificação independe da prática da estratégia de bonificação

$\mathrm{H}_{0,10}$ : a percepção de que o produto precisa competir com muitos produtos concorrentes para ser objeto de política de bonificação independe da prática da estratégia de bonificação

$\mathrm{H}_{0,11}$ : a percepção de que o produto precisa ter pequena margem de lucratividade para ser objeto de política de bonificação independe da prática da estratégia de bonificação

$\mathrm{H}_{0,12}$ : a percepção de que não deve haver fidelidade dos clientes ao produto para este ser objeto de política de bonificação independe da prática da estratégia de bonificação

$\mathrm{H}_{0,13}$ : 0 método de cálculo dos custos dos produtos independe da prática da estratégia de bonificação

O Quadro 3 sintetiza os principais resultados obtidos em todos os testes.

Quadro 3 - Resultados dos testes de independência entre variáveis

\begin{tabular}{|c|c|c|c|}
\hline TESTES & & & RESULTADOS \\
\hline 1 & & Custo das unidades de produtos bonificadas & Não rejeitar $\mathrm{H}_{0}$ \\
\hline 2 & & Benefício econômico das unidades recebidas como bonificação & Não rejeitar $\mathrm{H}_{0}$ \\
\hline 3 & \multirow{2}{*}{$\begin{array}{l}\text { Pontos negativos da utilização } \\
\text { da política de bonificação em } \\
\text { produtos }\end{array}$} & Não há nenhum ponto negativo relevante & Não rejeitar $\mathrm{H}_{0}$ \\
\hline 4 & & A imagem do produto fica prejudicada no mercado & Rejeitar $\mathrm{H}_{0}$ \\
\hline 5 & \multirow{5}{*}{$\begin{array}{l}\text { Características de um produto } \\
\text { para que ele seja objeto de } \\
\text { política de bonificação }\end{array}$} & As quantidades de produtos bonificados "matam" vendas futuras & Rejeitar $\mathrm{H}_{0}$ \\
\hline 6 & & Ter consumo rápido & Não rejeitar $\mathrm{H}_{0}$ \\
\hline 7 & & Capacidade de produção acima da demanda de mercado & Não rejeitar $\mathrm{H}_{0}$ \\
\hline 8 & & Baixo custo unitário total de produção & Não rejeitar $\mathrm{H}_{0}$ \\
\hline 9 & & Baixo custo unitário variável de produção & $\begin{array}{l}\text { Rejeitar } \mathrm{H}_{0} \text { ao } \\
\text { nível de } 7 \%\end{array}$ \\
\hline 10 & & 0 produto compete com muitos produtos concorrentes & Não rejeitar $\mathrm{H}_{0}$ \\
\hline 11 & & 0 produto tem pequena margem de lucratividade & Não rejeitar $\mathrm{H}_{0}$ \\
\hline 12 & & Não existe fidelidade dos clientes ao produto & Rejeitar $\mathrm{H}_{0}$ \\
\hline 13 & & Cálculo dos custos dos produtos & Não rejeitar $\mathrm{H}_{0}$ \\
\hline
\end{tabular}


Cumpre destacar que, devido à transformação realizada em al gumas variáveis, o tamanho reduzido da amostra não prejudicou a consistência dos resultados obtidos no teste qui-quadrado. Houve apenas dois testes em que a frequência esperada ficou ligei ramente abaixo de 5: teste 4, com uma frequência esperada de 4,88, e o teste 10, com uma frequência esperada de 4,47.

A Tabela 1 apresenta informações detalhadas dos testes em que $\mathrm{HO}$ foi rejeitada. Esta tabela corresponde aos testes de número 4, 5, 9 e 12 e evidencia as diferenças de opinião, em percentual, entre as empresas que praticam ou não a estratégia de bonificação, onde $C=$ concorda, $\mathrm{NCD}=$ não concorda nem discorda, $\mathrm{D}=$ discorda.

\section{CONCLUSÕES}

A fundamentação teórica apresentada neste trabal ho salienta que o custo do produto bonificado corresponde ao custo variável. Dessa forma, poderia existir uma tendência de se acreditar que, do ponto de vista do resultado da empresa, a política de bonificação seria mel hor que a política de desconto no preço. As argumentações teóricas atestam que 0 resultado econômico de ambas as políticas é igual. Para isso, é preciso que haja equivalência entre o percentual de bonificação e o percentual de desconto no preço.

O estudo empírico revelou que mais da metade das empresas da amostra adota a política de bonificação em quantidade de produtos. Nessas empresas, a decisão de desconto de quantidade versus desconto no preço é tomada pela área comercial e, em alguns casos, a área de finanças tem algum tipo de participação. Das empresas pesquisadas, $63 \%$ adotam a política de bonificação em quantidade de produto, e essa estratégia de bonificação é operacionalizada por meio da entrega de quantidade grátis do mesmo produto ou de produto diferente daquele vendido. Também é significativo o número de empresas (33,3\%) que empregam somente a bonificação em quantidade do próprio produto objeto da venda. Pode-se observar que o volume de produtos bonificados em relação ao total dos produtos vendidos não é muito elevado. $\mathrm{Na}$ maior parte dos casos, essa relação situa-se na faixa de zero a $5 \%$ das vendas.

De acordo com a percepção dos controllers, a empresa, por meio da política de bonificação em quantidade de produtos, busca atingir vários objetivos simultaneamente, todos considerados igualmente importantes: agregar val or à venda e facilitar a negociação com o cliente; fidelizar clientes; aumentar o volume de venda do período; fixar a marca; e, ainda, expandir a participação no mercado. 0 maior incentivo às empresas para adotarem a política de bonificação em quantidade, como alternativa à política de desconto no preço, diz respeito ao argumento de que o volume do produto colocado no mercado pela política de bonificação é maior do que pela política de desconto no preço, diminuindo a participação dos concorrentes. Outra questão percebida pelos gestores é de que o custo da bonificação para a empresa é menor do que o custo do desconto no preço. Tendo em vista a fundamentação teórica efetuada neste trabal ho, pode-se afirmar que não é correta a percepção de parte dos controllers que responderam à pesquisa, pois entendem que o custo da bonificação para a empresa é menor do que o custo do desconto no preço. Foi demonstrado que, dada a premissa de que um mesmo volume de produtos é entregue ao cliente, o resultado da decisão de bonificação em quantidades e o resultado do desconto no preço são exatamente iguais.

Grande parte desses controllers entende que o cliente não percebe o ben efício da bonificação como mais favorável que o benefício do desconto no preço. Por outro lado, quase $80,2 \%$ dos respondentes acreditam que o cliente percebe o benefício econômico das unidades bonificadas

Tabela 1 - Diferenças de opinião entre as empresas

\begin{tabular}{|c|c|c|c|c|c|c|}
\hline & \multicolumn{3}{|c|}{ ADOTA A POLITITCA } & \multicolumn{3}{|c|}{ NÃO ADOTA A POLIITICA } \\
\hline FRASES & C & NCD & D & C & NCD & $\mathrm{D}$ \\
\hline $\begin{array}{l}\text { Imagem do produto prejudicada no mercado com a política de } \\
\text { bonificação }\end{array}$ & 5,6 & 9,3 & 85,2 & 27 & 18,9 & 54,1 \\
\hline As quantidades de produtos bonificados "matam" vendas futuras & 22,2 & 29,6 & 48,1 & 56,8 & 18,9 & 24,3 \\
\hline $\begin{array}{l}\text { Necessário baixo custo unitário variável de produção para que um pro- } \\
\text { duto seja objeto de política de bonificação }\end{array}$ & 25,9 & 40,7 & 33,3 & 43,2 & 18,9 & 37,8 \\
\hline $\begin{array}{l}\text { Necessário não existir fidelidade dos clientes ao produto para este ser } \\
\text { objeto de bonificação }\end{array}$ & 25,9 & 27,8 & 46,3 & 48,6 & 35,1 & 16,2 \\
\hline
\end{tabular}


como sendo o preço de venda dos produtos recebidos. Essa percepção parece tecnicamente correta, uma vez que, sem conhecer o custo de produção das unidades recebidas em bonificação, o cliente deve avaliá-las pelo preço de venda das unidades compradas.

$\mathrm{N}$ a percepção dos gestores comerciais, as duas características principais que um produto deve ter para que seja objeto de bonificação em quantidades são estar competindo com muitos outros concorrentes e ter consumo rápido. $N$ ão existe consenso entre os controllers em relação aos pontos negativos da política de bonificação em produtos; nenhuma das alternativas apresentadas foi considerada importante. Do ponto de vista dos custos, a indicação majoritária dos controllers é de que a empresa calcula os custos dos produtos pelo custo total de fabricação por meio do critério legal. Esses gestores acreditam, de maneira coerente, que esse valor corresponde ao custo das unidades dadas como bonificação, mas as reflexões conceituais apresentadas demonstram que o custo do produto corresponde ao seu custo variável.

Os testes de independência realizados, relacionando os dois grupos de empresas (que adotam e que não adotam a política de bonificação em quantidade) com determinadas variáveis de interesse, destacam que os controllers dos dois grupos de empresas têm a mesma percepção sobre os seguintes pontos: (i) custo das unidades de produtos dadas como bonificação; (ii) benefício econômico das unidades dadas como bonificação; (iii) não-identificação de nenhum ponto negativo na utilização da política de bonificação; (iv) necessidade de o produto ter consumo rápido para ser objeto da política de bonificação em quantidade; (v) necessidade de a empresa ter capacidade de produção acima da demanda de mercado para praticar a política de bonificação em quantidade; (vi) necessidade de o produto ter baixo custo unitário total de produção para ser objeto da política de bonificação; (vii) necessidade de o produto competir com muitos produtos concorrentes para ser objeto da política de bonificação; (viii) necessidade de o produto ter pequena margem de lucratividade para ser objeto da política de bonificação; e (ix) a forma de cálculo dos custos dos produtos empregada pela empresa. Por outro lado, os controllers dos dois grupos de empresas não têm a mesma percepção sobre os seguintes pontos: (i) se a imagem do produto fica prejudicada com a política de bonificação; (ii) se as quantidades dadas em bonificação "matam" vendas futuras; (iii) se o produto precisa ter baixo custo unitário variável de produção para ser objeto de política de bonificação; e (iv) se não deve haver fidel idade dos clientes ao produto para que este seja objeto de bonificação.
Como limitações deste estudo, destacam-se o baixo retorno de questionários respondidos (apenas 15\% das empresas selecionadas participaram da pesquisa) e o enfoque restrito a setores de atividade específicos. A ampliação da amostra e a definição de outros ramos de atividade são sugestões que poderiam ser contempladas em estudos futuros sobre 0 assunto.

\section{REFERÊNCIAS}

AAKER, D. A; KUMAR, V; DAY, G. S. M arketing research. 5. ed. N ew York: John Wiley, 1995.

ARCELUS, F. J; SHAH, N. H; SRINIVASAN, G. Retailers's response to special sales: price discount vs. trade credit. Omega, v. 29, n. 5, p. 417-428, 2001.

BUSSAB, W. 0; MORETTIN, P. A. Estatística básica, 5. ed. São Paulo: Saraiva, 2002.

SCHIFF, A. I; SCHIFF, J. B; SCHIFF, M. Marketing costs: back to basics. Financial Executive, v. 7, n. 3, p. 34-37, 1991.

FARHAMGMHER, M; BRITO, P. Q. As promoções de venda: definições, teoria e a percepção dos gestores. Revista Portuguesa de M arketing, ano 1, n. 4, p. 35-42, 1997.

FOSTER, G; GUPTA, M. Marketing, cost management and management accounting. Journal of Management Accounting Research, v. 6, p. 43-61, 1994.

FRIEDMAN, H. H; LEWIS, B. J. Dynamic pricing strategies for maximizing customer satisfaction. The National Public Accountant, v. 44, n. 1, p. 8-9, 1999.

GOLDRATT, E. M. A síndrome do palheiro: garimpando informação num oceano de dados. São Paulo: Educator, 1992.

GUERREIRO, R; ANGELO, C. F. Modelo de decisão de preços e rentabilidade sob a base conceitual de gestão econômica (Gecon). Revista de Contabilidade do CRC-SP, p. 34-42, 1999.

GUERREIRO, R; SANTOS, A; GISBRECHT, J. A. S; ONG, B. S. Cost implications of bonus pack promotions versus price discounts. American Business Review, v. 22, n. 1, p. 72-81, 2004.

GURNANI, H. A study of quantity discount pricing models with different ordering structures: order coordination, order consolidation, and multitier ordering hierarchy. International Journal of Production Economics, v. 72, n.3, p. 203-225, 2001. 
HORNGREN, C. T. Cost accounting: a managerial emphasis. 3. ed. New Jersey: Prentice Hall, 1972.

JOHNSON, M. D; HERRMANN, A; BAUER, H. H. The effects of price bundling on consumer evaluations of product offerings. International Journal of Research in Marketing, v. 16, n. 2, p. 129-142, 1999.

KASS, P. The rise of discount: how to survive the profit squeeze. British Food Journal, v. 96, n. 2, p. 18-32, 1994.

KOPALLE, P. K; MELA, C. F; MARSH, L. The dynamic effect of discounting on sales: empirical analysis and normative pricing implications. M arketing Science, v. 18, n. 3, p. 317-332, 1999.

MARTINS. E. Contabilidade de custos. 9. ed. São Paulo: Atlas, 2003.

MUNGER, J. L; GREWAL, D. The effects of alternative price promotional methods on consumers' product evaluation and purchase intentions. Journal of Product and Brand Management, v. 10, n. 3, p. 185-197, 2001.
NOREEN, E; SMITH, D; MACKEY, j. T. The theory of constraints and its implications for management accounting. Great Barrington: The North River Press, 1995.

ONG, B. S; HO, F. N; TRIPP, C. Consumer perceptions of bonus packs: an exploratory analysis. Journal of Consumer Marketing, v. 14, n. 2, 1997.

REITER, J. What a deal!M ore processors are using value-style packaging to gain a competitive edge. Dairy Foods Magazine, v. 95, n. 2, p. 62-5, 1994.

SEIBERT, L. J. W hat consumers think about bonus pack sales promotions. Marketing N ews, v. 31, n. 4, p. 9, Feb. 1997.

SMITH, M. F; SINHA, I. The impact of price and extra product promotions on store preference. International Journal of Retail and Distribution Management, v. 28, n. 2, p. 83-92, 2000.

SCHIFF, A. I; SCHIFF, J. B; SCHIFF, M. Marketing costs: back to basics. Financial Executive, v. 7, n. 3, p. 34-37, 1991.

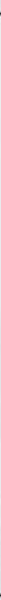

\section{A revista on-line da comunidade brasileira de pesquisa em Administração.}

Artigos científicos inéditos, de alta qualidade e com acesso totalmente aberto. 